\title{
Is there a need to shield ulcers after endoscopic submucosal dissection in the gastrointestinal tract?
}

Authors

Institution
Ichiro Oda, Satoru Nonaka, Seiichiro Abe, Haruhisa Suzuki, Shigetaka Yoshinaga, Yutaka Saito

Endoscopy Division, National Cancer Center Hospital, Tokyo, Japan submitted 17. March 2015 accepted after revision 23. March 2015

\section{Bibliography}

DOI http://dx.doi.org/

$10.1055 / \mathrm{s}-0034-1392032$

Endoscopy International Open

2015; 03: E152-E153

(c) Georg Thieme Verlag KG

Stuttgart · New York

E-ISSN 2196-9736

\section{Corresponding author}

Ichiro Oda, MD

Endoscopy Division

National Cancer Center Hospital

5-1-1 Tsukiji

Chuo-ku

Tokyo 104-0045

Japan

Fax: +81-3-35423815

ioda@ncc.go.jp
Endoscopic submucosal dissection (ESD) is accepted as a less invasive method of local resection of gastrointestinal tract neoplasia with a negligible risk of lymph node metastasis. ESD facilitates en bloc resection even in patients with larger or ulcerated lesions, thereby preserving the organ and improving the patient's quality of life compared with surgery. However, it is associated with various complication risks such as bleeding, perforation, and stricture formation. The ESD procedure was originally developed for early gastric cancer in the mid-1990 s. Several technical refinements have been made in recent years and its indications have expanded to other organs and several clinical conditions. Consequently, several specific complications have arisen and need to be addressed.

In this issue of Endoscopy International Open, Takao et al. report the healing process of ESD-induced ulcers treated by the endoscopic application of polyglycolic acid (PGA) sheets with fibrin glue in a porcine model [1]. The PGA sheet is a biodegradable material that can be hydrolyzed in vivo and absorbed within approximately 15 weeks. Fibrin glue is a tissue adhesive composed of human fibrinogen and thrombin. The combined use of PGA sheets and fibrin glue has already been applied in many surgical fields with several reports on their safety and efficacy [2-5]. However, there have been few reports on the endoscopic application of PGA sheets with fibrin glue for post-ESD ulcers in the gastrointestinal tract [ $6-11]$. In this animal study reported by Takao et al., this tissue shielding technique has been safely applied to post-ESD ulcers [1].

Tissue shielding using PGA sheets and fibrin glue might be useful for the prevention of several specific complications associated with ESD. First, it can be applicable for the prevention of delayed perforation after duodenal ESD as Takimoto et al. and Doyama et al. have reported in small case series $[6,7]$. Delayed perforation after duodenal endoscopic resection occurs in $6 \%$ of cases which is significantly higher than for any other site in the gastrointestinal tract because of the thin duodenal wall and direct exposure of the post-ESD ulcer to bile and pancreatic juices [12]. In addition, delayed perforation in the duodenum can be fatal and hence effective prophylactic therapy is imperative. Second, tissue shielding using PGA sheets and fibrin glue can also be applicable for the prevention of stricture formation after esophageal ESD as lizuka et al. and Sakaguch et al. have reported with promising results $[8,9]$. A mucosal defect occupying more than three-fourths of the circumference is a risk factor for stricture formation with the frequency of stricture after such esophageal ESD reported to be $66-92 \%[13,14]$. Esophageal strictures can require multiple endoscopic dilations which can cause a substantial decrease in the patient's quality of life. Although the efficacy of local injection and oral administration of steroids has been reported for the prevention of post-ESD strictures $[14,15]$, these methods involve a risk of severe adverse effects such as delayed perforation and serious infections $[16,17]$. Third, Tsuji et al. reported a pilot study of the shielding method with PGA sheets and fibrin glue for the prevention of delayed perforation and bleeding after colorectal ESD [10]. Delayed perforation is a serious complication because it often requires emergency surgical intervention. However, the necessity of this preventive shielding method in the colon may be limited compared to other sites (duodenum and esophagus) at the current time, considering the low incidence of delayed perforation after colorectal ESD, which is reported to be $0.4 \%$ [18]. Fourth, patients receiving antithrombotics including antiplatelet and anticoagulant medications are also possible candidates for the shielding method with PGA sheets and fibrin glue to prevent delayed bleeding after gastric ESD. As the proportion of the elderly in society has increased, the number of patients re- 
ceiving antiplatelet and/or anticoagulant medications has also been increasing. A recent study reported that delayed bleeding was significantly higher in patients with single $(15.5 \%, 9 / 58)$ or dual antiplatelet therapy $(35.5 \%, 11 / 31)$ than in patients without any antiplatelet therapy $(6.1 \%, 16 / 261)$ [19]. Oral anticoagulants are replaced with heparin (heparin bridging therapy) before high risk endoscopic procedures. However, a high incidence of delayed bleeding was also reported in patients on heparin bridging therapy $(37.5 \%, 9 / 24)[20]$.

In addition, tissue shielding can be applicable for the management of delayed perforation after ESD of early gastric cancer. Delayed perforation after gastric ESD is a rare complication so it is impractical to prophylactically shield post-ESD ulcers after every procedure. Although perforation during gastric ESD can be treated conservatively using endoscopic clips, emergency surgical intervention is frequently required for delayed perforation. Ono et al. reported a successful application of PGA sheets for delayed perforation after gastric ESD [11].

ESD should be safe, effective, and suitable in a variety of clinical situations. Consequently, the shielding method using PGA sheets and fibrin glue is a promising method for the prevention and management of several specific complications related to ESD although, so far, there have only been case reports or small case series. Regarding the technical aspects at the current time, it is still challenging to deliver PGA sheets on post-ESD ulcers because of the location and gravitational influence. Larger prospective studies as well as technical improvements are necessary.

\section{Competing interests: None}

\section{References}

1 Takao T, Takegawa Y, Shinya $N$ et al. Tissue shielding using polyglycolic acid sheets and fibrin glue on ulcers induced by endoscopic submucosal dissection in a porcine model. Endosc Int Open 2015; 03: DOI 10.1055/s-0034-1391391

2 Uemura K, Murakami Y, Hayashidani Y et al. Combination of polyglycolic acid felt and fibrin glue for prevention of pancreatic fistula following pancreaticoduodenectomy. Hepatogastroenterology 2009; 56: $1538-1541$

3 Sugawara T, Itoh $Y$, Hirano $Y$ et al. Novel dural closure technique using polyglactin acid sheet prevents cerebrospinal fluid leakage after spinal surgery. Neurosurgery 2005; 57: 290-294

4 Yano T, Haro A, Shikada Y et al. A unique method for repairing intraoperative pulmonary air leakage with both polyglycolic acid sheets and fibrin glue. World J Surg 2012; 36: 463-467

5 Shinozaki T, Hayashi R, Ebihara $M$ et al. Mucosal defect repair with a polyglycolic acid sheet. Jpn J Clin Oncol 2013; 43: 33-36
6 Takimoto K, Toyonaga T, Matsuyama K. Endoscopic tissue shielding to prevent delayed perforation associated with endoscopic submucosal dissection for duodenal neoplasms. Endoscopy 2012; 44: E414-E415

7 Doyama H, Tominaga K, Yoshida $N$ et al. Endoscopic tissue shielding with polyglycolic acid sheets, fibrin glue and clips to prevent delayed perforation after duodenal endoscopic resection. Dig Endosc 2014; 26: $41-45$

8 Iizuka T, Kikuchi D, Yamada A et al. Polyglycolic acid sheet application to prevent esophageal stricture after endoscopic submucosal dissection for esophageal squamous cell carcinoma. Endoscopy 2015; 47: $341-344$

9 Sakaguchi Y, Tsuji Y, Ono $S$ et al. Polyglycolic acid sheets with fibrin glue can prevent esophageal stricture after endoscopic submucosal dissection. Endoscopy 2015; 47: 336-340

10 Tsuji Y, Fujishiro M, Kodashima $S$ et al. Polyglycolic acid sheets and fibrin glue decrease the risk of bleeding after endoscopic submucosal dissection of gastric neoplasms (with video). Gastrointest Endosc 2015; 81: 906-912

11 Ono H, Takizawa K, Kakushima $\mathrm{N}$ et al. Application of polyglycolic acid sheets for delayed perforation after endoscopic submucosal dissection of early gastric cancer. Endoscopy 2015; 47: E18 - 19

12 Inoue T, Uedo $N$, Yamashina $T$ et al. Delayed perforation: a hazardous complication of endoscopic resection for non-ampullary duodenal neoplasm. Dig Endosc 2014; 26: 220-227

13 Ezoe Y, Muto M, Horimatsu $T$ et al. Efficacy of preventive endoscopic balloon dilation for esophageal stricture after endoscopic resection. J Clin Gastroenterol 2011; 45: 222-227

14 Hanaoka $N$, Ishihara $R$, Takeuchi $Y$ et al. Intralesional steroid injection to prevent stricture after endoscopic submucosal dissection for esophageal cancer: a controlled prospective study. Endoscopy 2012; 44: $1007-1011$

15 Yamaguchi N, Isomoto H, Nakayama T et al. Usefulness of oral prednisolone in the treatment of esophageal stricture after endoscopic submucosal dissection for superficial esophageal squamous cell carcinoma. Gastrointest Endosc 2011; 73: 1115-1121

16 Yamashina T, Uedo N, Fujii $M$ et al. Delayed perforation after intralesional triamcinolone injection for esophageal stricture following endoscopic submucosal dissection. Endoscopy 2013; 45: E92

17 Ishida T, Morita $Y$, Hoshi $N$ et al. Disseminated nocardiosis during systemic steroid therapy for the prevention of esophageal stricture after endoscopic submucosal dissection. Dig Endosc 2015; 27: 388 - 391

18 Saito Y, Uraoka T, Yamaguchi Yet al. A prospective, multicenter study of 1111 colorectal endoscopic submucosal dissections (with video). Gastrointest Endosc 2010; 72: 1217-1225

19 Tounou S, Morita Y, Hosono T. Continuous aspirin use does not increase post-endoscopic dissection bleeding risk for gastric neoplasms in patients on antiplatelet therapy. Endosc Int Open 2015; 03: E31 -E38

20 Yoshio T, Nishida T, Kawai $N$ et al. Gastric ESD under heparin replacement at high-risk patients of thromboembolism is technically feasible but has a high risk of delayed bleeding: Osaka University ESD Study Group. Gastroenterol Res Pract 2013: 365830 